\title{
Fatigue Design Evaluation of Railway Bogie with Full-Scale Fatigue Test
}

\author{
Jung-Won Seo, Hyun-Moo Hur, Hyun-Kyu Jun, Seok-Jin Kwon, and Dong-Hyeong Lee
}

Korea Railroad Research Institute, Uiwang, Gyeonggi-do 437-755, Republic of Korea

Correspondence should be addressed to Jung-Won Seo; jwseo@krri.re.kr

Received 12 October 2016; Accepted 22 December 2016; Published 8 February 2017

Academic Editor: Paolo Ferro

Copyright (c) 2017 Jung-Won Seo et al. This is an open access article distributed under the Creative Commons Attribution License, which permits unrestricted use, distribution, and reproduction in any medium, provided the original work is properly cited.

\begin{abstract}
The bogie frame of a railway is an important structural member for the support of vehicle loading. In general, more than 25 years' durability is necessary. Much study has been carried out in experimental and theoretical domains on the prediction of the structural integrity of the bogie frame. The objective of this paper is to estimate the structural integrity of the bogie frame of an electric railcar. Strength analysis has been performed by finite element analysis. From this analysis, stress concentration areas were investigated. To evaluate the loading conditions, dynamic stress was measured by strain gauge. It has been found that the stress and strain due to the applied loads were multiaxial conditions according to the location of the strain gauge. Fatigue strength evaluations of the bogie frame were performed to investigate the effect of a multiaxial load through the employment of a critical plane approach.
\end{abstract}

\section{Introduction}

The bogies of railway vehicles consist of bogie frames, suspensions, axles, and wheels. The shapes of bogies as well as the load conditions, such as static load and dynamic load, are complex. Therefore, various tests including static load tests, fatigue tests, and track tests are required for the design and the strength evaluation of the bogie [1-4]. The bogie frame is required to last 25 years or longer as the main structure that supports loads of the vehicle body. Although the UIC, EN, and JIS standards [5-7] prescribe the strength evaluation methods of bogie frames, they do not define detailed fatigue life assessment approaches.

EN 13789 [5] defines the static load and the fatigue load to evaluate the strength of bogie frames. The fatigue test in the laboratory requires the load magnitude and cycles to guarantee 30 years within an annual mileage of $200,000 \mathrm{~km}$ [5]. However, the load magnitude may vary according to the vehicle type and track conditions. Excessive definition of the load conditions in the fatigue test may make weight reduction and the optimization of bogie frames difficult $[8,9]$. If the load conditions of the fatigue test are lower than those of the in-service track, the fatigue damage and the crack may occur during the operation of the railway vehicle. The EN standard requires the fatigue life to be evaluated by track test. The fatigue life evaluation is required to be conducted in accordance with the cumulative damage rule, but the detailed evaluation method has not been specified. In particular, the fatigue life evaluation method for multiaxial load has not been defined. Therefore, a number of detailed studies on the fatigue life evaluation of bogie frames have been conducted $[1,10,11]$. However, there have been few studies on the fatigue life evaluation method and the characteristics of the stress history that occur in the fatigue test and the track test.

In this study, the static load test, fatigue test, and track test were conducted to evaluate the fatigue strength of bogie frames that were used in electric railcars. The characteristics of the load history obtained on track test were evaluated. The load conditions in Korea were compared to those of EN 13798 and the fatigue damage was assessed by applying various fatigue evaluation methods.

\section{Finite Element Analysis and Static Test of Bogie Frames}

2.1. Finite Element Model. Figure 1(a) shows a driving bogie used in an electric vehicle. A rubber spring is used as the primary suspension and an air spring is used as the secondary 


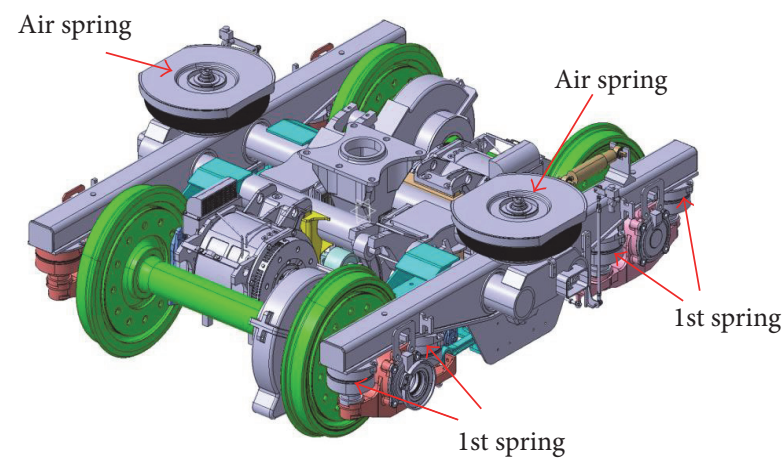

(a) Driving bogie

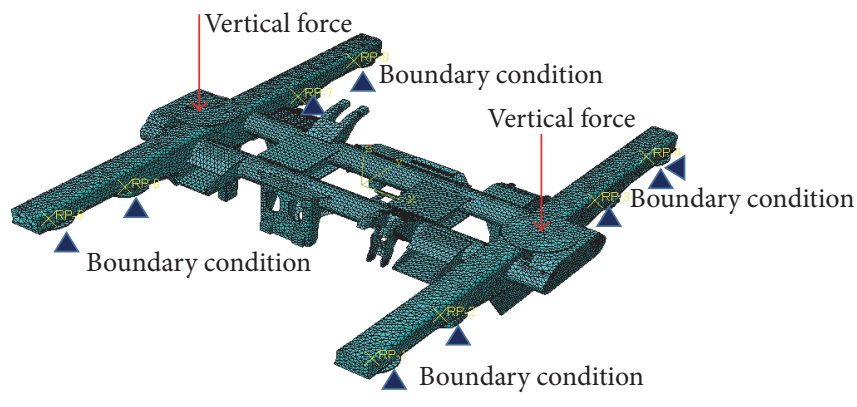

(b) Finite element model of bogie frame

FIgURE 1: Driving bogie and finite element model.

TABLE 1: Load case for static test.

\begin{tabular}{|c|c|c|c|c|}
\hline \multirow{2}{*}{ Load case } & \multirow{2}{*}{ Load conditions } & \multirow{2}{*}{ Load $(\mathrm{kN})$} & \multicolumn{2}{|c|}{ Boundary condition } \\
\hline & & & Load point & Support point \\
\hline \multirow{8}{*}{ Exceptional load } & Vertical force & 171.9 & Air spring & 1st spring \\
\hline & Transverse force & 127.6 & Lateral buffer & 1st spring \\
\hline & Longitudinal force & 231.0 & Center pivot & 1st spring \\
\hline & Lozenging forces & 42.1 & Wheel point & 1st spring + center pivot \\
\hline & Twist load & 51.7 & Air spring & 1st spring \\
\hline & $\begin{array}{l}\text { Traction motor } \\
\text { Inertia load }\end{array}$ & 127.5 & Traction motor bracket & 1st spring \\
\hline & Traction motor load & 180.8 & Traction motor bracket & 1st spring \\
\hline & Emergency braking load & 15.9 & Braking bracket & 1st spring \\
\hline \multirow{4}{*}{ Normal service load } & Vertical force & 100.0 & Air spring & 1st spring \\
\hline & Transverse force & 69.3 & Lateral buffer & 1st spring \\
\hline & Lozenging forces & 13.9 & Wheel point & 1st spring + center pivot \\
\hline & Twist load & 26.0 & Air spring & 1st spring \\
\hline
\end{tabular}

suspension. As it is a driving bogie, it has a traction motor and a disc brake is used as the brake system. Figure 1(b) shows a finite element model of the bogie frame. For the modeling, shell elements were used. The number of elements was 51,811, and the number of nodes was 47,356.

2.2. Load Conditions. The static loads can be divided in accordance with EN 13798 into the exceptional loads and the normal service loads. Table 1 shows the static loads calculated according to EN 13798. The exceptional loads can be divided into nine cases and the normal service loads are divided into four cases. Vertical forces were applied at the air springs and the 1st springs were constrained as boundary conditions. Transverse forces were applied at the lateral buffers, and the 1st springs were constrained. Table 1 shows the boundary conditions for each load.

Table 2 shows the mechanical properties of the materials used in the bogie frame. The main frame material of the bogie is SM490A, the transom pipe is STKM18B, and the bracket is made from SS400. The stress occurring in the bogie frame on exceptional loads should be less than the yield strength of the material used. Under the normal service loads, the mean
TABLE 2: Mechanical properties.

\begin{tabular}{lccc}
\hline Material & $\begin{array}{c}\text { Yielding } \\
\text { strength } \\
(\mathrm{MPa})\end{array}$ & $\begin{array}{c}\text { Tensile } \\
\text { strength } \\
(\mathrm{MPa})\end{array}$ & Remark \\
\hline SM490A & 325 & 490 & $\begin{array}{c}\text { Side frame, T/M mounting } \\
\text { bracket, transom support, gear } \\
\text { mounting bracket }\end{array}$ \\
STKM18B & 315 & 490 & $\begin{array}{c}\text { Transom } \\
\text { SS400 }\end{array}$ \\
\hline
\end{tabular}

stress and the stress amplitude are calculated on each load and they should be within the fatigue limit diagram.

$$
\begin{aligned}
\sigma_{m} & =\frac{\sigma_{\max }+\sigma_{\min }}{2}, \\
\sigma_{a} & =\frac{\sigma_{\max }-\sigma_{\min }}{2}
\end{aligned}
$$

where $\sigma_{\max }$ is the maximum stress, $\sigma_{\min }$ is the minimum stress, $\sigma_{m}$ is the mean stress, and $\sigma_{a}$ is the stress amplitude. 
Results: 1- B.C. 1, Strees 1 , vertical stress - Von mises min: 0 max: 125 frame of REF: part

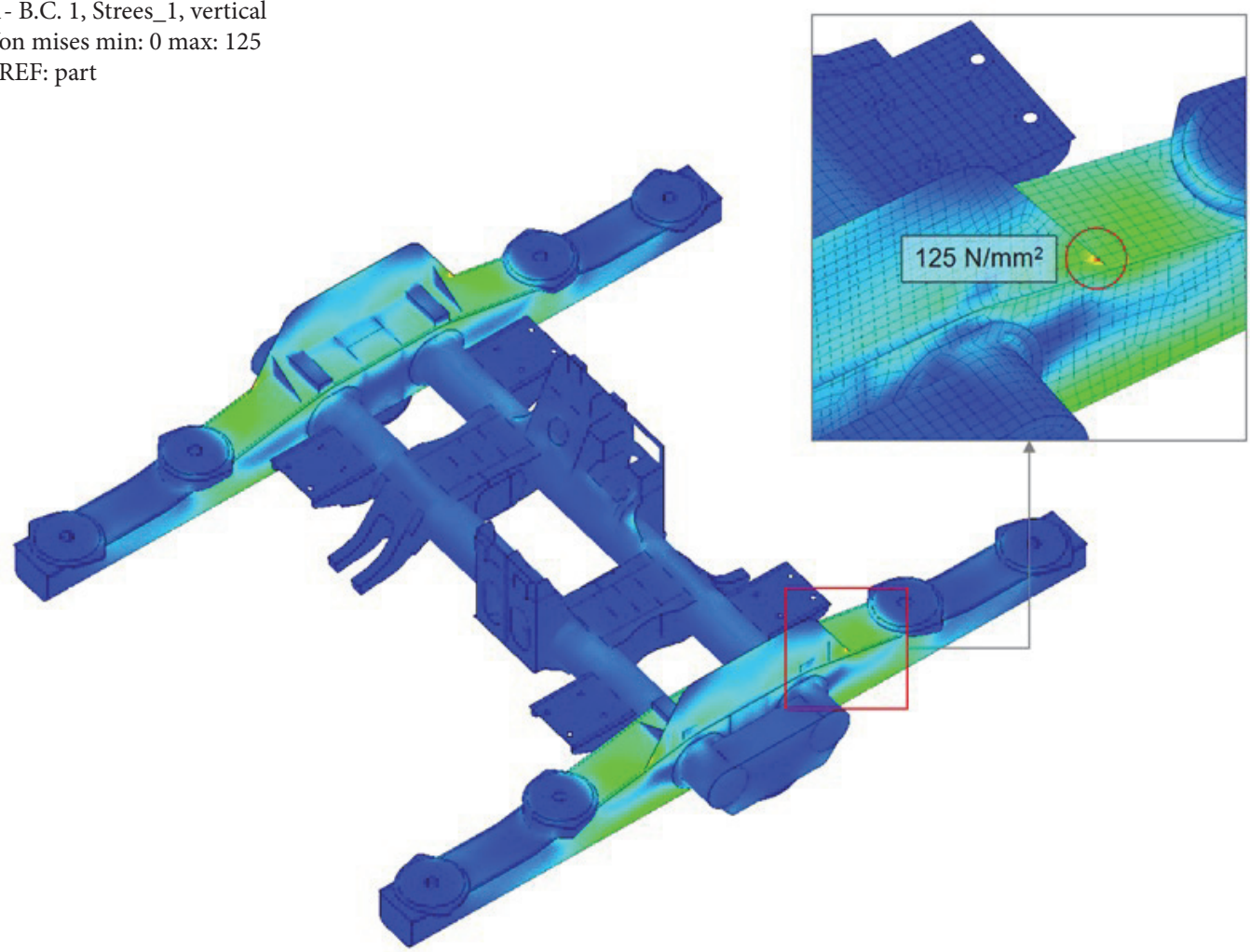

Value option: actual shell surface: top

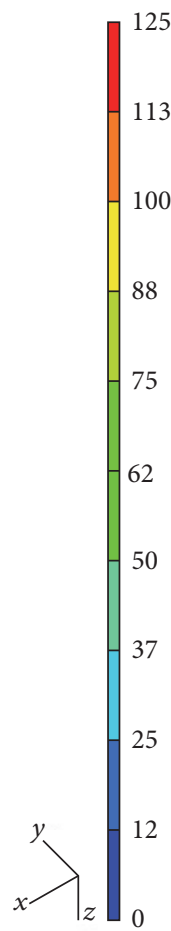

Figure 2: Maximum stress of the bogie frame under vertical Load.

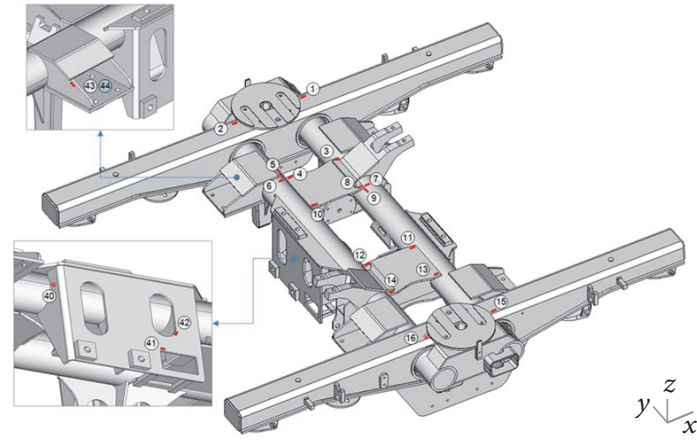

(a) Upper location

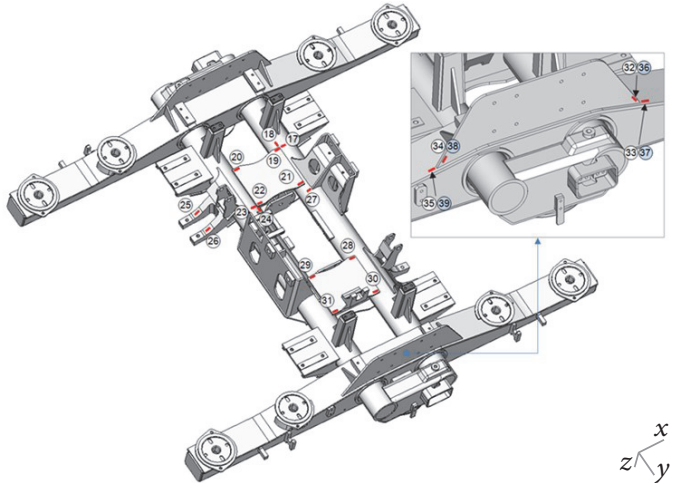

(b) Lower location

FIGURE 3: Strain gauge location for static test.

2.3. Static Load Test. For the static load test, the areas where high stress occurred in each load condition should be predicted. Therefore, the finite element analysis was conducted under the same conditions as the static load test. Figure 2 shows the result of the finite element analysis when vertical load is applied. The maximum stress occurred on the bracket attached under the side frame. Figure 3 shows the locations where strain gauges were attached for the static load test. Those locations were selected from the result of the finite element analysis for each load condition. Strain gauges were attached to a total of 44 locations.
Table 3 shows the result of the static load test on the exceptional loads. On the vertical load, the compressive load of $-127 \mathrm{MPa}$ occurred at the point (gauge location No. 2) that is located on the upper side frame, and $113 \mathrm{MPa}$ occurred on the connection (gage location No. 37) between the side frame and the bracket. The maximum stress of $125 \mathrm{MPa}$ from the result of finite element analysis occurred on the connection between the side frame and the bracket, which was a similar result. On transverse load, the maximum stress occurred at the point (gauge location No. 2) which is located on the upper side frame, which was the compressive stress. The 
TABLE 3: Measured maximum stress for static test.

\begin{tabular}{|c|c|c|c|c|c|c|}
\hline Load case & Load conditions & Maximum stress (MPa) & Yielding strength (MPa) & Safety factor & Material & Gauge no. \\
\hline \multirow{2}{*}{1} & \multirow{2}{*}{ Vertical force } & -127 & 325 & 2.56 & SM490A & 02 \\
\hline & & 113 & 325 & 2.87 & SM490A & 37 \\
\hline \multirow{2}{*}{2} & \multirow{2}{*}{ Transverse force } & -114 & 325 & 2.85 & SM490A & 02 \\
\hline & & 104 & 325 & 3.13 & SM490A & 38 \\
\hline \multirow{2}{*}{3} & \multirow{2}{*}{ Longitudinal force } & 95 & 315 & 3.32 & STKM18A & 32 \\
\hline & & 84 & 325 & 3.86 & SM490A & 36 \\
\hline 4 & Lozenging forces & -87 & 325 & 3.74 & SM490A & 02 \\
\hline 5 & Twist load & -93 & 325 & 3.49 & SM490A & 42 \\
\hline 6 & $\begin{array}{c}\text { Traction motor } \\
\text { Inertia load }\end{array}$ & -106 & 325 & 3.01 & SM490A & 10 \\
\hline 7 & Traction motor load & -93 & 325 & 3.49 & SM490A & 01 \\
\hline 8 & Emergency braking load & -107 & 325 & 3.04 & SM490A & 02 \\
\hline 9 & Active steering force & 140 & 315 & 2.25 & STKM18A & 32 \\
\hline $10^{*}$ & Vertical + transverse force & 123 & 325 & 2.64 & SM490A & 34 \\
\hline $11^{*}$ & Vertical + transverse + twist force & 135 & 325 & 2.41 & SM490A & 34 \\
\hline
\end{tabular}

${ }^{*}$ Combined load at normal service load.

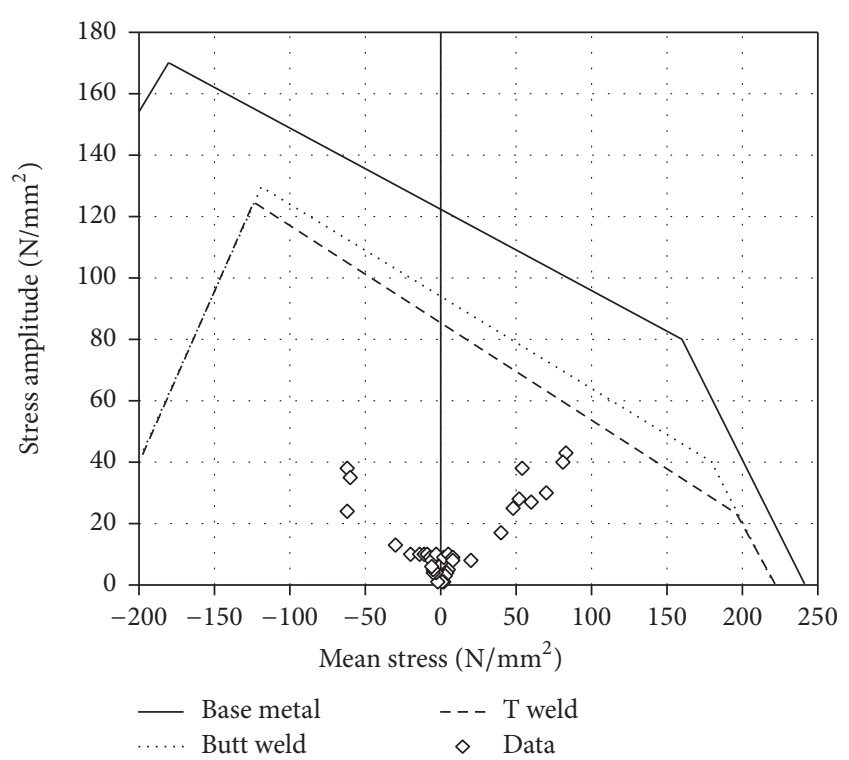

FIGURE 4: Goodman diagram with the results of service static load.

maximum tensile stress occurred on the connection between the side frame and the bracket. Under the normal service load conditions, each load to be applied is combined. Table 3 shows that the load conditions of Nos. 10 and 11 are the normal service load conditions. The maximum stress occurred on the connection between the frame and the bracket. The stress that occurred under exceptional loads was less than the yield strength, which was considered to be safe.

Figure 4 shows the result of evaluating the fatigue limit diagram after the mean stress and the stress amplitude were calculated under the normal service load conditions. The stress amplitude and the mean stress were calculated for each

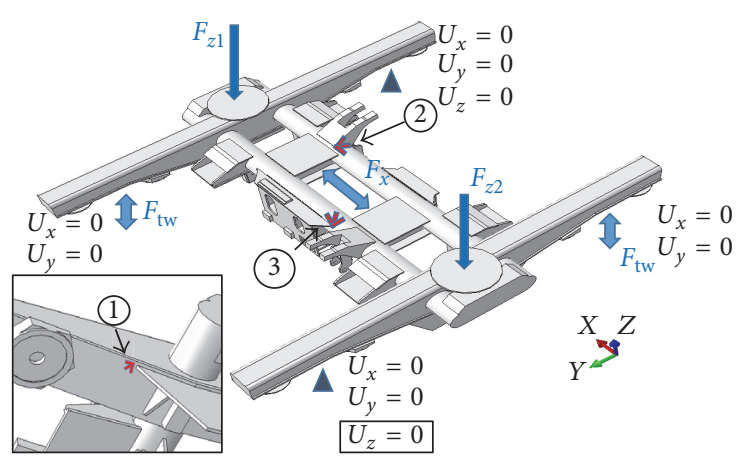

FIGURE 5: Load conditions and strain gauge locations.

combined load. Stresses of all areas where the strain gauges are attached are within the safe area. Therefore, the fatigue strength is assessed to be safe.

\section{Fatigue Test and Track Test}

3.1. Fatigue Test. The fatigue test of the bogie frame for electric railcars was conducted according to EN 13749. Figure 5 shows the load conditions consisting of the vertical load $\left(F_{z}\right)$, the transverse load $\left(F_{x}\right)$, and the twist load $\left(F_{\mathrm{tw}}\right)$. In the fatigue test, the loads are composed of the static load, the quasi-static load, and the dynamic load:

(i) a static part $F_{z 1}=F_{z 2}=F_{z} / 2$,

(ii) a quasi-static part $F_{z 1}=F_{z 2}= \pm \alpha F_{z} / 2$,

(iii) a dynamic part $F_{z 1}=F_{z 2}= \pm \beta F_{z} / 2$,

where $\alpha$ is the roll coefficient, which indicates the load at the curve track, and 0.1 was applied. $\beta$ is the bounce coefficient, which indicates the dynamic load, and 0.2 was applied. The 


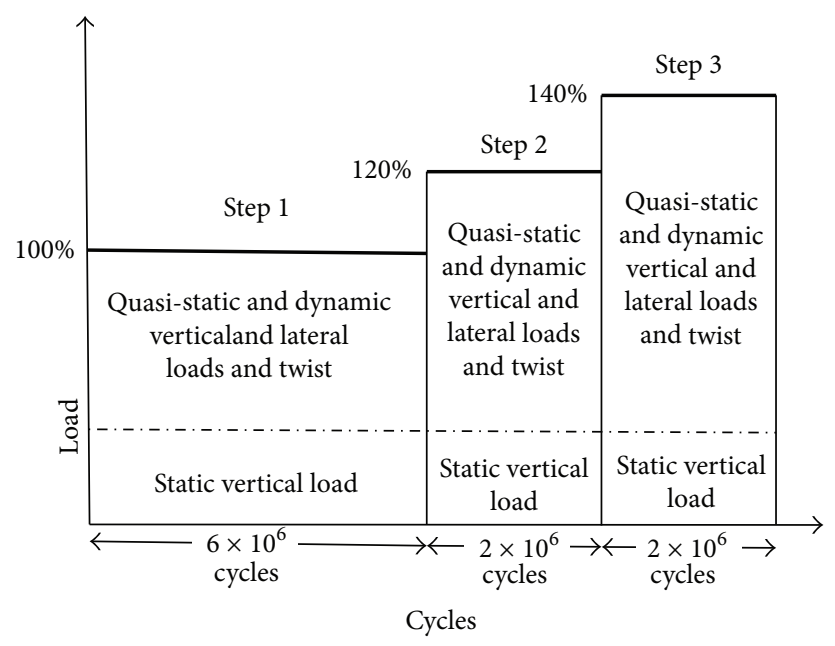

FIGURE 6: Step-by-step load conditions of fatigue test [6].

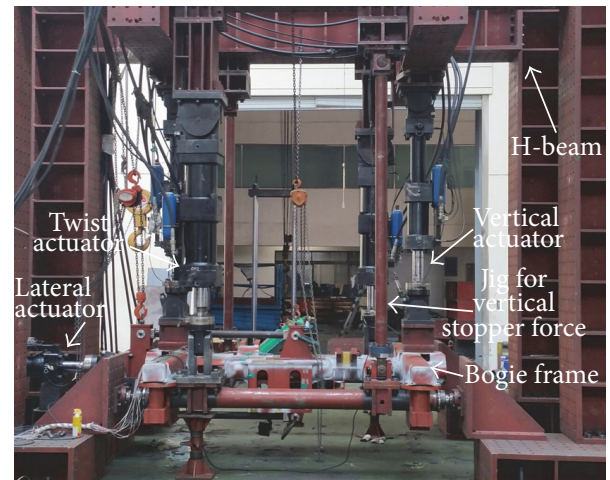

FIgURE 7: Equipment and specimen for fatigue test.

strain gauges were attached to evaluate the characteristics of the stress history in the fatigue test. The strain gauges were attached to the areas where the maximum stress occurred from the result of the static load test.

Figure 6 shows the load condition for fatigue tests according to EN 13749. In step 1, the fatigue test was conducted by applying an initial load up to $6 \times 10^{6}$ cycles. In step 2 , the quasi-static load and dynamic load were increased by 1.2 times and the fatigue test was conducted up to $2 \times 10^{6}$ cycles. In step 3, the quasi-static load and the dynamic load were increased by 1.4 times and the fatigue test was conducted up to $2 \times 10^{6}$ cycles. After the fatigue test in step 1 and 2 , cracks should not occur, while very small cracks are permitted in step 3.

Figure 7 shows the test equipment for the fatigue test. The equipment has two actuators for vertical load, one actuator for transverse load, and two actuators for twist load. Figure 8 shows a graph of the fatigue load history in step 1 . The quasistatic load and the dynamic load were applied for the vertical load, after the static load was applied. The quasi-static load for the curve track was applied differently to the left and right.
The load magnitude changed every 10 cycles. The quasi-static load and the dynamic load were applied to the transverse load. The twist load was applied every 10 cycles. Figure 9 shows the result of nondestructive testing (magnetic particle inspection) after the fatigue test. The nondestructive testing was conducted from steps 1 to 3 , and no cracks were evident.

3.2. Track Test. To evaluate the fatigue life of bogie frames for electric railcars, a track test was conducted by using similar bogie frames on an in-service track. The strain gauges were attached to the same locations shown in Figure 5, to compare it with the fatigue test. Figure 10 shows the test vehicle and the data acquisition system for measuring the strain for the track test. The test was performed with the data acquisition system which is MGCplus made by HBM, and the sampling rate was set to $600 \mathrm{~Hz}$. The test distance was $30 \mathrm{~km}$, and the track test was conducted in the same conditions as in-service conditions.

\section{Test Results and Discussions}

4.1. Stress Analysis. This section assesses and compares the stress characteristics occurring in the fatigue test and the track test. Figure 5 shows the location of Points 1, 2, and 3 for comparison of the fatigue test and track test results. Strain gauges were attached to the location where the stresses were large in the static load test. Figure 11 shows the strain history that occurs at Point 1 in the fatigue test. In the fatigue test, vertical load, transverse load, and twist load are applied, with changing every ten cycles. Therefore, Figure 11 shows that the strain repeats the identical shape every ten cycles. Figure 12 describes the strain history that occurs at Point 1 in the track test. The strain history that occurs in the track test shows random shapes. Since the static load is included in the fatigue test, the maximum strain that occurs is greater in the fatigue test than in the track test. However, because the track test does not include static load, the mean strain is close to " 0 ". 




Figure 8: Load history of fatigue test in step 1.



FIGURE 9: Nondestructive testing after fatigue test.

The biaxiality ratio $(\lambda)$ is applied as the parameter to evaluate the local stress conditions $[13,14] . \lambda$ is defined as follows:

$$
\lambda=\frac{\sigma_{2}}{\sigma_{1}}
$$

where $\lambda$ is the biaxiality ratio, and $\sigma_{1}$ is the maximum principal stresses, while $\sigma_{2}$ is the minimum principal stresses.

Figure 13 shows the changes in $\lambda$ and its principal stress of Point 1 in the fatigue test. $\lambda$ for all principal stresses is distributed around zero and the direction of the principal stress is distributed around $30^{\circ}-45^{\circ}$. This is uniaxial and is the proportional loading condition. Figure 14 shows the changes in $\lambda$ of Point 1 and its principal stress in the track test. Although $\lambda$ is generally distributed between -1 and
1, the stresses with large principal stresses are distributed in " 0 ". Moreover, the direction of the principal stress with large stresses is fixed at $40^{\circ}$. This is uniaxial and in the same proportion as in the fatigue test. Even though in the case of Point 1, the stresses that occur in the fatigue test and the track test differ from each other in terms of the stress magnitude, the stress conditions are uniaxial, and the direction of principal stresses is similar.

Figure 15 shows the changes in $\lambda$ of Point 3 and its principal stress in the fatigue test. $\lambda$ varies from -0.8 to 0 , and the direction of its principal stress changes from $20^{\circ}$ to $40^{\circ}$. This is the multiaxial and the nonproportional loading condition. Figure 16 shows the changes in $\lambda$ of Point 3 and its principal stress in the track test. $\lambda$ is generally distributed between -1 and 1 , and the direction of the principal stress changes from $0^{\circ}$ to $90^{\circ}$. This is the multiaxial and the nonproportional loading condition, the same as in the fatigue test.

Therefore, since the stresses of the bogie frame are the multiaxial and the nonproportional loading condition, the fatigue life evaluation should be done by taking this into account.

4.2. Fatigue Life Evaluation. Since the load characteristics can vary in accordance with the vehicle type and track conditions, the stresses characteristics of the bogie frames of electric railcars running in Korea were investigated. 




(a)

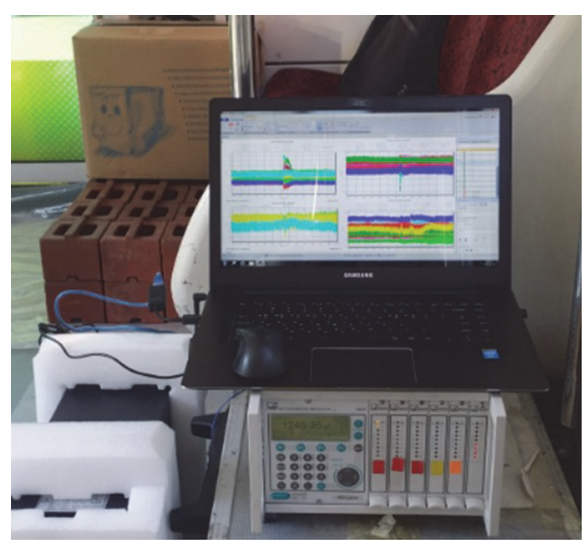

(b)

FIgURE 10: Test vehicle and data acquisition system for track test.


FIgURE 11: Strain occurring in fatigue test (Point 1).

Figure 17 shows comparisons of the stress magnitudes occurring in the fatigue test and the track test. To compare with the fatigue test, the track test was presented by converting the cycle into the case of 30 years of running within the annual mileage of $200,000 \mathrm{~km}$. To do this, the rainflow cycle counting method was used. In both cases, the maximum magnitude of the stress range appears similarly, as shown in Figure 17. Nonetheless, in the fatigue test, the cycle of stresses with a large stress range occurs often.

It is difficult to directly compare both the fatigue test and the track test with the result of cycle counting as shown in Figure 17. Therefore, the equivalent stress range applied in IIW [15] was used, and the formula is as follows:

$$
\begin{aligned}
& \Delta \mathrm{S}_{\mathrm{eq}} \\
& \quad=\sqrt[m_{1}]{\frac{1}{D} \frac{\sum\left(N_{i} \cdot \Delta S_{i}^{m_{1}}\right)+\Delta S_{L d}^{\left(m_{1}-m_{2}\right)} \cdot \sum\left(N_{j} \cdot \Delta S_{j}^{m_{2}}\right)}{\sum N_{i}+\sum N_{j}}},
\end{aligned}
$$
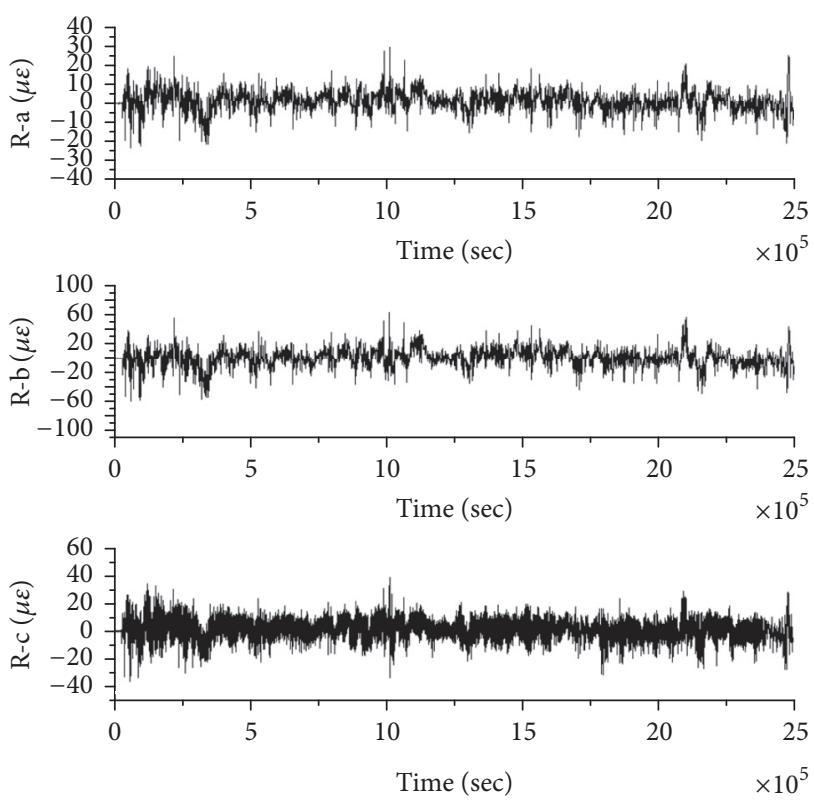

FIGURE 12: Strain occurring in track test (Point 1).

where $\Delta S_{\text {eq }}$ is the equivalent stress range, $D$ is the Miner sum, $m_{1}$ is the slope of the upper part of the knee point on the $S-N$ curve, $m_{2}$ is the slope of the lower part of the knee point on the $S-N$ curve, $\Delta S_{i}$ is the stress range of the upper part of the knee point at level $i$ of the $S$ - $N$ curve, $\Delta S_{j}$ is the stress range of the lower part of the knee point at level $\mathrm{j}$ of the S-N curve, $\Delta S_{L d}$ is the stress range of the knee point on the $S$ - $N$ curve, $N_{i}$ is the number of cycles of $\Delta S_{i}$, and $N_{j}$ is the number of cycles of $\Delta S_{j}$.

Table 4 shows the stresses that occur in the fatigue test and the track test in the equivalent stress range. In the case of Point 1 with the largest stress, the equivalent stress range of fatigue test with $23.89 \mathrm{MPa}$ is much larger than that of track test with 4.21 MPa. In the case of Point 3, it is assessed that the equivalent stress range of the two tests is similar. Since the fatigue test result is larger than the track test result, the 

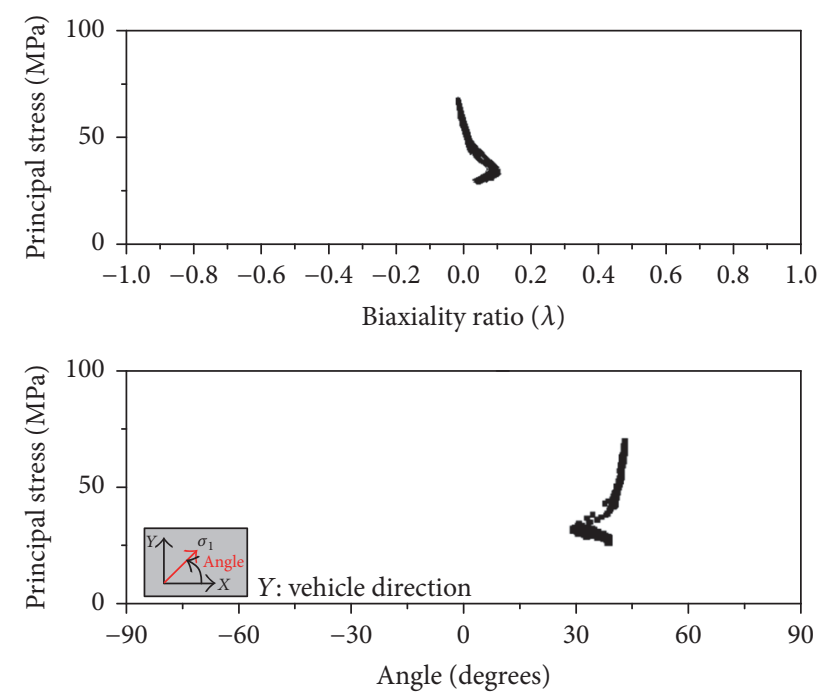

- Fatigue test

FIGURE 13: Changes in principal stress in fatigue test (Point 1).
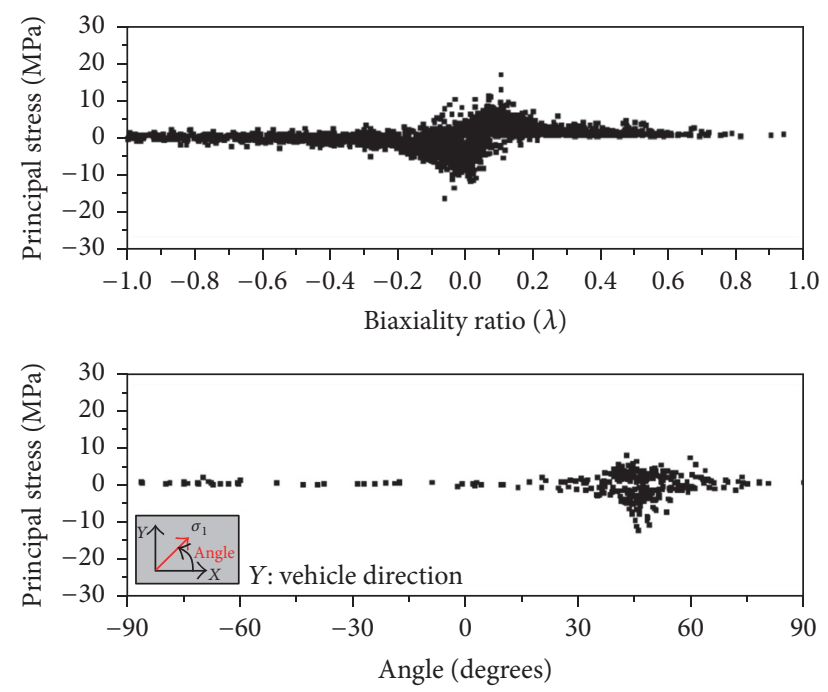

- Track measurement

FIGURE 14: Changes in principal stress in track test (Point 1).

TABLE 4: Comparison of equivalent stress range in fatigue test and track test.

\begin{tabular}{lccc}
\hline Case & $\begin{array}{c}\text { Point 1 } \\
(\mathrm{MPa})\end{array}$ & $\begin{array}{c}\text { Point 2 } \\
(\mathrm{MPa})\end{array}$ & $\begin{array}{c}\text { Point 3 } \\
(\mathrm{MPa})\end{array}$ \\
\hline Fatigue test & 23.89 & 9.78 & 4.14 \\
Track test & 4.21 & 4.12 & 4.07 \\
\hline
\end{tabular}

load conditions specified for the fatigue test in EN 13749 can be evaluated to be sufficiently conservative compared to the domestic track conditions.

The fatigue life was evaluated based on the stresses occurring in the fatigue test and the track test. For the fatigue life evaluation on welded joints, the method by BS7608 [16] was
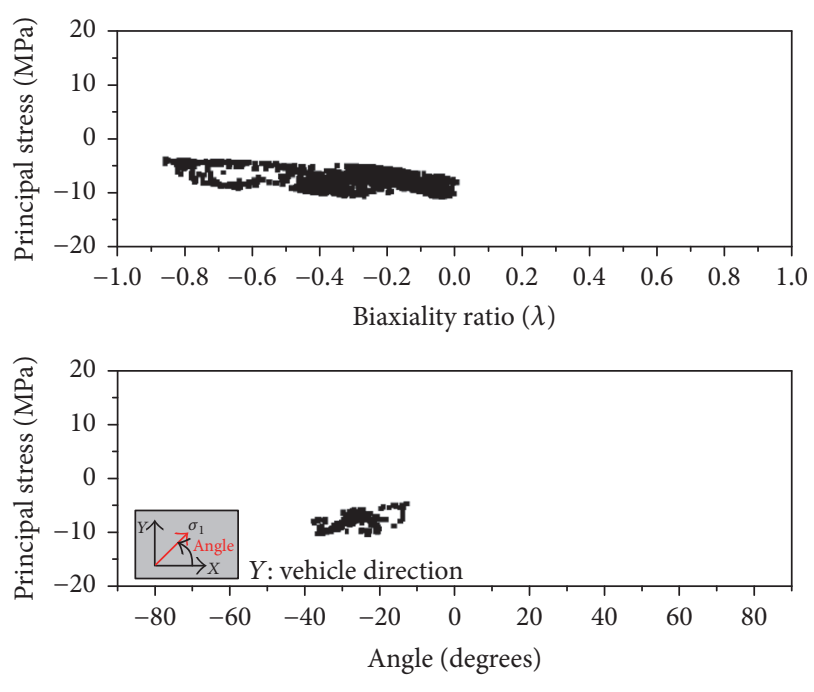

- Fatigue test

Figure 15: Changes in principal stress in fatigue test (Point 3).
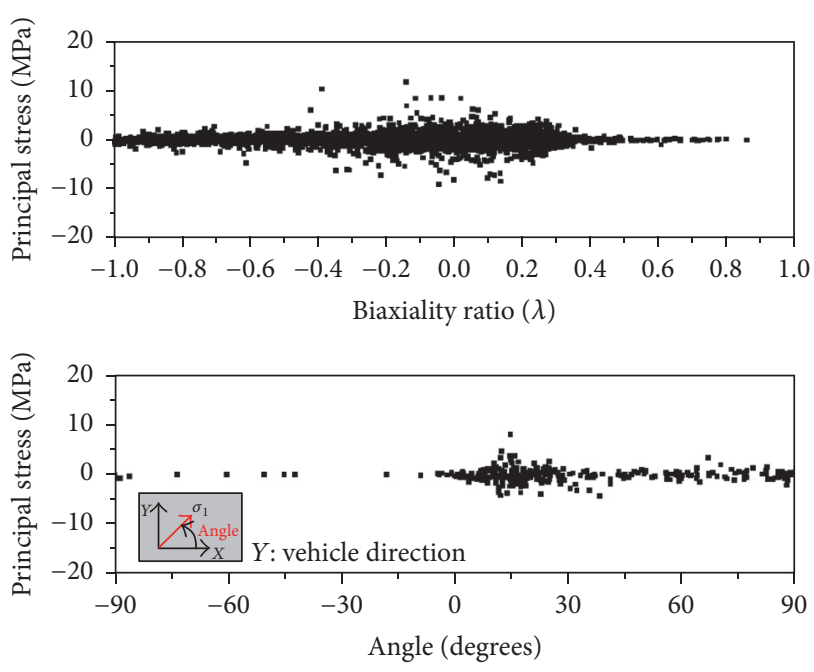

- Track measurement

Figure 16: Changes in principal stress in track test (Point 3).

used. Under BS7608, the $S-N$ curves are classified according to each class and the nominal stress is applied. In the case of tubular nodal joints, the $S-N$ curve to which the hot-spot stress is applied is given. In addition, according to welding configurations, the fatigue notch factors should be used and it is obtained through stress analysis or measurement. Since the configuration of the bogie frame at the strain gauge point falls under Class $\mathrm{F}$, the $S$ - $N$ curve for the fatigue life evaluation that was used was Class F. When the measurement location is far enough from the welded toe, the measured stresses can be assumed as the nominal stress. When this is not the case, since the fatigue life is evaluated conservatively, revisions to this are needed. Figure 18 shows the definition of stresses in welded joints [17].

To take into account the stress concentration in welded joints, finite element analysis was carried out and Figure 19 
TABLE 5: Comparison of fatigue damage between lab test and track test.

\begin{tabular}{llccc}
\hline Location & \multicolumn{2}{c}{ Fatigue test } & Track test & Remark \\
\hline \multirow{3}{*}{ Point 1} & 1st load step & 0.07 & & Track test: in-service track \\
& 2nd load step & 0.20 & 0.02 & Distance/year: $2 \times 10^{5}$ \\
& 3rd load step & 0.46 & & Life: 30 years \\
\hline
\end{tabular}

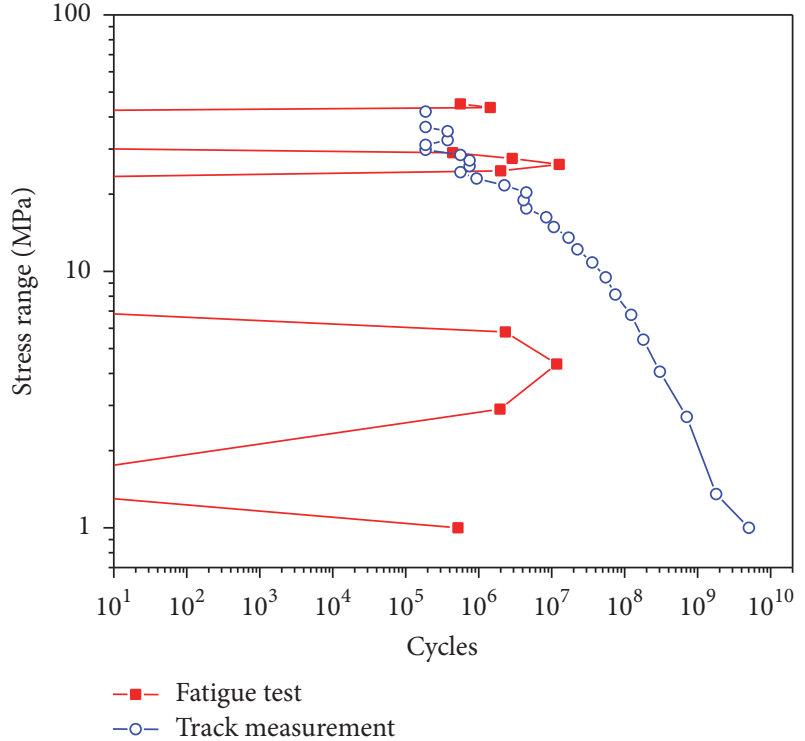

Figure 17: Comparison of cycle counting results in fatigue test and track test (Point 1$)$.

shows the finite element model. Figure 20 shows the longitudinal stress distribution and the weld toe is the location where the maximum stress occurs. The hot spot stress can be obtained by extrapolating the stress of the location that is 0.5 $x t$ away from the welded end, and the stress of the location that is $1.5 \times t$ away from the welded end as shown in Figure 20 . In this case, the hot spot stress is $100.9 \mathrm{MPa}$, the nominal stress is $100 \mathrm{MPa}$, and the maximum stress is $271.1 \mathrm{MPa}$. The maximum stress by welded joint notch can be represented as follows [17, 18]:

$$
\begin{aligned}
\sigma_{\text {peak }} & =K_{t} \times \sigma_{n}=\left(K_{s} \times K_{w}\right) \times \sigma_{n}=\left(K_{s} \times \sigma_{n}\right) \times K_{w} \\
& =\sigma_{h s} \times K_{w},
\end{aligned}
$$

where $\sigma_{\text {peak }}$ is the maximum stress, $\sigma_{n}$ is the nominal stress, $\sigma_{h s}$ is the hot spot stress, $K_{t}$ is the stress concentration factor, $K_{w}$ is the stress concentration factor caused by the weld bead, and $K_{s}$ is the structural stress concentration factor.

Thus, the stress concentration factor can be obtained from the analysis as follows:

$$
\begin{gathered}
K_{t}=\frac{271.1}{100}=2.71, \\
K_{w}=\frac{271.1}{100.9}=2.69 .
\end{gathered}
$$

Table 5 shows the results of calculating the fatigue damage in the fatigue test and the track test. In the fatigue test, the
TABLE 6: Material properties for fatigue analysis [12].

\begin{tabular}{lccccc}
\hline$E(\mathrm{GPa})$ & $v$ & $\sigma_{f}^{\prime}(\mathrm{MPa})$ & $\varepsilon_{f}^{\prime}(\%)$ & $b$ & $c$ \\
\hline 209 & 0.3 & 927 & 0.656 & -0.084 & -0.73 \\
\hline
\end{tabular}

TABLE 7: Comparison of fatigue damage according to the fatigue evaluation method.

\begin{tabular}{lccc}
\hline Location & $\begin{array}{c}\text { Normal } \\
\text { strain }\end{array}$ & SWT & Remark \\
\hline Point 1 & 1.00 & 0.98 & Normalization to \\
Point 2 & 1.00 & 0.95 & compare results \\
Point 3 & 1.00 & 0.86 & \\
\hline
\end{tabular}

fatigue damage was assessed with each load step. In the case of the fatigue test, the least fatigue damage occurred in the first step, while the fatigue damage increased in the second and the third steps. Although the load magnitude in the second step increases to 1.2 times that of the first step, the fatigue damage increases to 2.9 times. In the third step, compared to the first step, the load magnitude increases to 1.4 times but the fatigue damage increases to 6.6 times. In the track test, the fatigue damage is 0.02 , which is smaller than that of the fatigue test. Therefore, among the three steps under EN 13749, it is determined that the load magnitude of the second and the third steps is specified more conservatively than that of in-service running conditions.

As in the stress distribution in Figures 13-16, stress conditions of the bogie frame have multiaxial stress characteristics according to the measurement locations in Figure 5. To evaluate the fatigue damage in the multiaxial condition, (6) of the normal strain and (7) of S.W.T were used [19-21].

$$
\begin{aligned}
\frac{\Delta \varepsilon}{2} & =\frac{\sigma_{f}^{\prime}}{E}\left(2 N_{f}\right)^{b}+\varepsilon_{f}^{\prime}\left(2 N_{f}\right)^{c}, \\
\sigma^{\max } \frac{\Delta \varepsilon_{1}}{2} & =\frac{\left(\sigma_{f}^{\prime}\right)^{2}}{E}\left(2 N_{f}\right)^{2 b}+\sigma_{f}^{\prime} \varepsilon_{f}^{\prime}\left(2 N_{f}\right)^{b+c},
\end{aligned}
$$

where $\sigma_{f}^{\prime}$ and $b$ are the fatigue strength coefficient and the fatigue strength exponents and $\varepsilon_{f}^{\prime}$ and $c$ are the fatigue ductility coefficient and the fatigue ductility exponents, respectively, and the values used for the analysis are as shown in Table 6 [12].

Table 7 contains the results of the fatigue damage in accordance with the evaluation methods. In the normal strain method, the total strain amplitude is calculated without considering the multiaxial condition and the fatigue damage is calculated. When the principal stress varies with time as in Point 3, it should be evaluated in consideration of the 


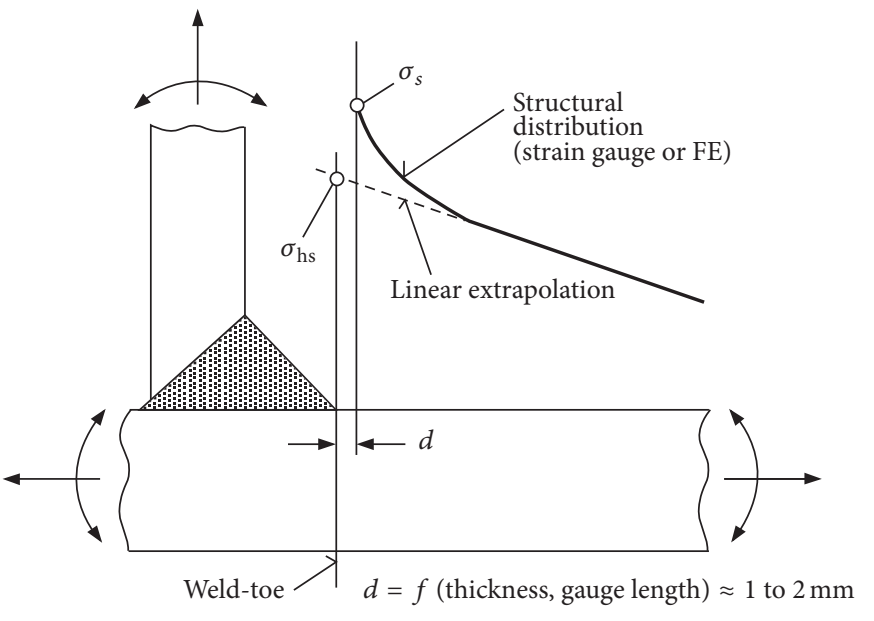

$\sigma_{s}:$ structural stress

$\sigma_{\text {hs }}:$ hot-spot-stress

$\sigma_{x}:$ maximum notch stress

$\sigma: f($ weld geometry, loading mode)

FIgURE 18: Stress definition in welded joints [17].

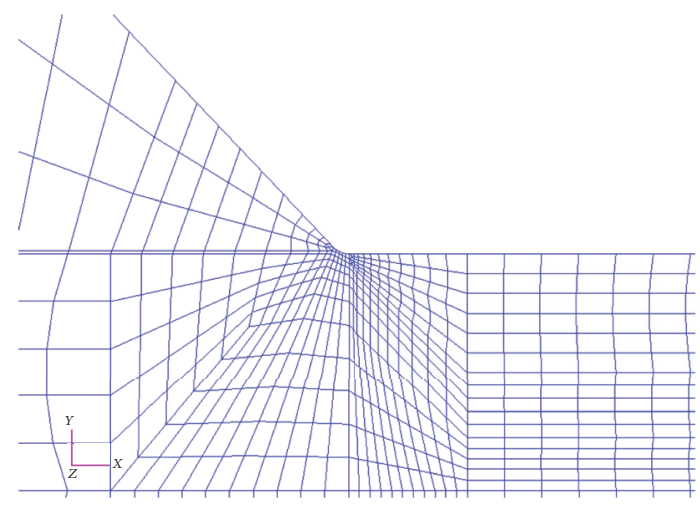

FIGURE 19: Weld toe configuration.

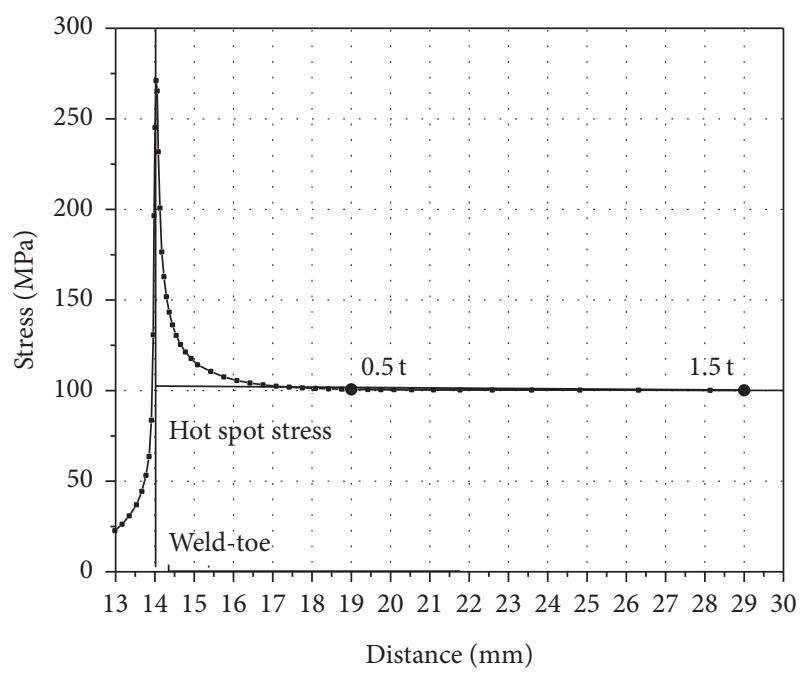

FIgURE 20: Longitudinal stress distribution. multiaxial condition. In the SWT method, the normal strain amplitude and the maximum normal stress on the plane are calculated in each plane to account for the multiaxial conditions. The accumulation of fatigue damage on all possible planes is calculated and the critical plane with the largest damage is selected. By normalization based on the normal strain method, the fatigue damage is compared. In the case of Point 1 , since it is uniaxial and in the proportional condition as in Figure 14, the fatigue damages in both the normal strain method and the SWT method are evaluated similarly. However, as for Point 3 , since it is multiaxial and in the nonproportional condition, as in Figure 16, there are differences in the fatigue damage. Therefore, to evaluate the fatigue strength of the bogie frame, it is determined that the appropriate fatigue evaluation methods should be applied, depending on the locations and stress conditions.

\section{Conclusion}

In this paper, to evaluate the fatigue strength of the bogie frames of electric railcars, the static load test, fatigue test, and track test were performed. The load conditions occurring under the track test of Korea and the load conditions specified under the fatigue test of EN 13798 were compared and the differences between them were examined. The characteristics of stress history in the fatigue test and the track test were evaluated and various fatigue life evaluation methods were applied. The following conclusions were obtained:

(1) Since the stresses that occurred as a result of the static load test on the bogie frame were within the yield strength of the materials, the bogie frame satisfies the requirements for static strength safety.

(2) The fatigue test was conducted and it was proven that since no cracks occurred until the third step load, 
the bogie frame has adequate strength against fatigue loads.

(3) The stresses that occur on the bogie frame are multiaxial and under nonproportional load, according to their locations. Therefore, to evaluate the fatigue strength of the bogie frame, it is determined that appropriate fatigue evaluation methods should be applied, depending on the locations and stress conditions.

(4) The fatigue damage was evaluated with the stresses that occurred in the fatigue test and the track test. It is considered that, among the three step loads under EN 13749, the load magnitudes of the second and the third steps are specified more conservatively than those of the in-service running conditions.

\section{Competing Interests}

The authors declare that they have no conflict of interests regarding the publication of this paper.

\section{Acknowledgments}

This research was supported by a grant from the R\&D Program of the Korea Railroad Research Institute, Republic of Korea.

\section{References}

[1] M. Kassner, "Fatigue strength analysis of a welded railway vehicle structure by different methods," International Journal of Fatigue, vol. 34, no. 1, pp. 103-111, 2012.

[2] J.-W. Han, J.-D. Kim, and S.-Y. Song, "Fatigue strength evaluation of a bogie frame for urban maglev train with fatigue test on full-scale test rig," Engineering Failure Analysis, vol. 31, pp. 412-420, 2013.

[3] H.-K. Jun, J.-W. Seo, S.-J. Kwon, D.-H. Lee, and S.-H. Park, "Effect of corrosion on the fatigue life of aged EMU under fatigue loading," International Journal of Precision Engineering and Manufacturing, vol. 17, no. 1, pp. 73-79, 2016.

[4] W. G. Lee, J. S. Kim, H. J. Yoon, K. B. Shin, and S. I. Seo, "Structural behavior evaluation of T-joints of the composite bogie frame under bending," International Journal of Precision Engineering and Manufacturing, vol. 14, no. 1, pp. 129-135, 2013.

[5] UIC Code 615-4, "Movie power units bogies and running gear bogie frame structure strength tests," International Union of Railway, 1994.

[6] EN 13749, "Railway applications-wheelsets and bogiesmethods of specifying structural requirements of bogie frames," European Committee for Standardization, 2011.

[7] JIS E7105, “Test methods for static load of body structures of railways rolling stock," Japanese Industrial Standard, 1994.

[8] J.-H. Kim, K.-B. Shin, and J.-S. Kim, "Optimum design on suspension joint parts of GFRP composite bogie frame with $\mathrm{H}$-shaped side beams for urban railway trains," International Journal of Precision Engineering and Manufacturing, vol. 13, no. 1, pp. 71-76, 2012.

[9] H.-J. Kim, H. Cho, H.-S. Jung, T.-S. Kwon, and M.-W. Suh, "Crashworthiness design and evaluation on the leading-cab structure of rolling stock using topology optimization," International Journal of Precision Engineering and Manufacturing, vol. 10, no. 2, pp. 79-85, 2009.

[10] A. Esderts, J. Willen, and M. Kassner, "Fatigue strength analysis of welded joints in closed steel sections in rail vehicles," International Journal of Fatigue, vol. 34, no. 1, pp. 112-121, 2012.

[11] K.-W. Jeon, K.-B. Shin, and J.-S. Kim, "Evaluation of tensioncompression and tension-tension fatigue life of woven fabric glass/epoxy laminate composites used in railway vehicle," International Journal of Precision Engineering and Manufacturing, vol. 12, no. 5, pp. 813-820, 2011.

[12] J. Seo, S. Kwon, Y. Ham, and S. Kwon, "The Fatigue life evaluation and load history measurement for Bogie frame of locomotive," in Proceedings of the Autumn Conference of Korean Society of Mechanical Engineers, vol. 11, pp. 378-383, 2008.

[13] M. Quaresimin, L. Susmel, and R. Talreja, "Fatigue behaviour and life assessment of composite laminates under multiaxial loadings," International Journal of Fatigue, vol. 32, no. 1, pp. 2-16, 2010.

[14] M. Quaresimin and P. A. Carraro, "On the investigation of the biaxial fatigue behaviour of unidirectional composites," Composites Part B: Engineering, vol. 54, pp. 200-208, 2013.

[15] A. Hobbacher, "Recommendations for fatigue design of welded joints and components," International Institute of Welding (IIW) Document XIII-2151r4/XV-1254r4-07, WRC-Bulletin 520, Welding Research Council, 2009.

[16] BS 7608, "Code of practice for fatigue design and assessment of steel structures," British Standard, 1993.

[17] C. M. Sonsino and M. Kueppers, "Multiaxial fatigue of welded joints under constant and variable amplitude loadings," Fatigue \& Fracture of Engineering Materials \& Structures, vol. 24, no. 5, pp. 309-327, 2001.

[18] W. Fricke and H. Paetzoldt, "Fatigue strength assessment of scallops -an example for the application of nominal and local stress approaches," Marine Structures, vol. 8, no. 4, pp. 423-447, 1995.

[19] M. Bäckström and G. Marquis, "A review of multiaxial fatigue of weldments: experimental results, design code and critical plane approaches," Fatigue and Fracture of Engineering Materials and Structures, vol. 24, no. 5, pp. 279-291, 2001.

[20] S. Kang and W. Kim, "A proposed S-N Curve for Welded ship structures-a hot-spot stress-based design S-N curve for fillet weld joints takes into account the effects of static cargo loads," Welding Journal, vol. 82, no. 7, pp. 161-169, 2003.

[21] B. Atzori and G. Meneghetti, "Fatigue strength of fillet welded structural steels: finite elements, strain gauges and reality," International Journal of Fatigue, vol. 23, no. 8, pp. 713-721, 2001. 

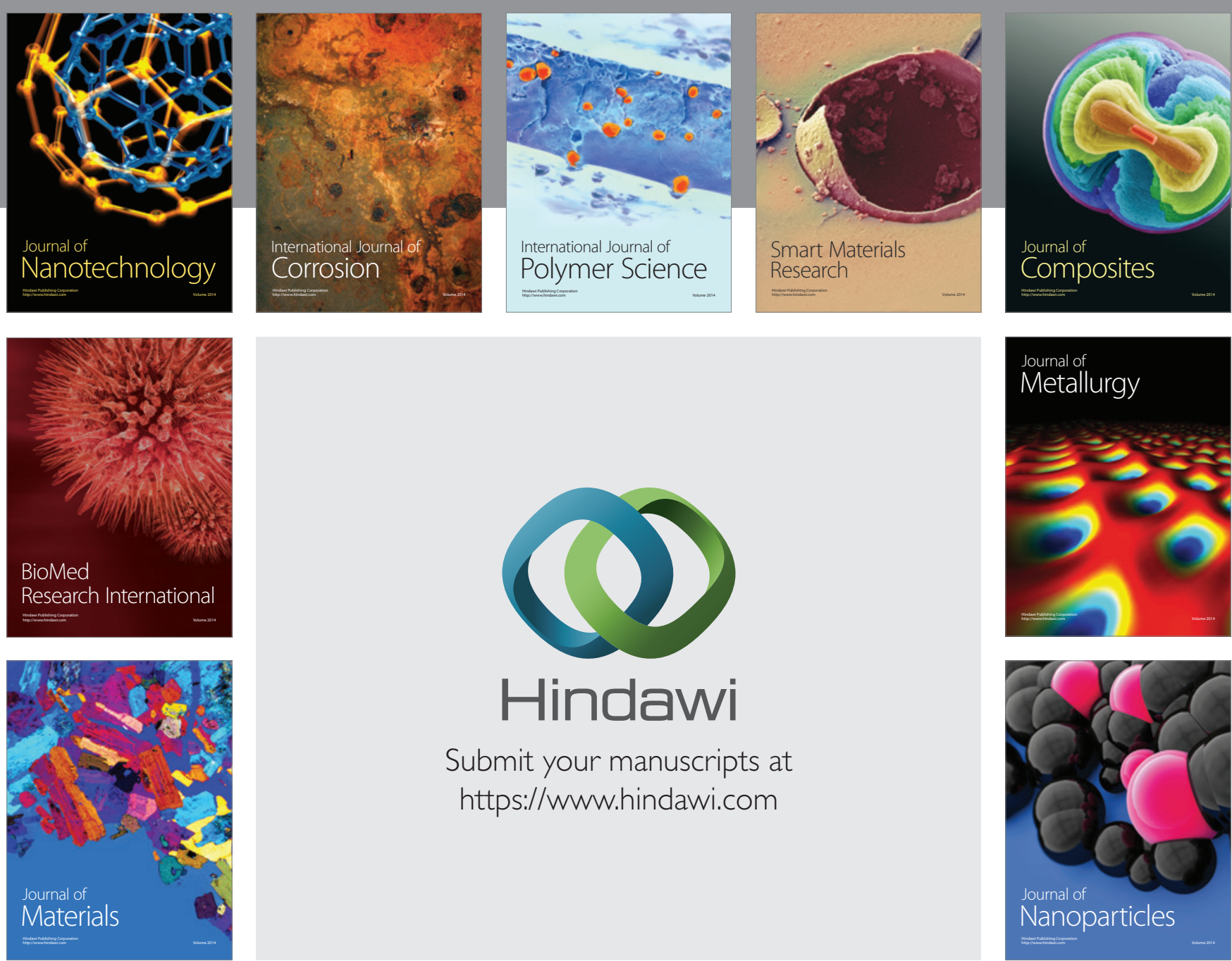

\section{Hindawi}

Submit your manuscripts at

https://www.hindawi.com

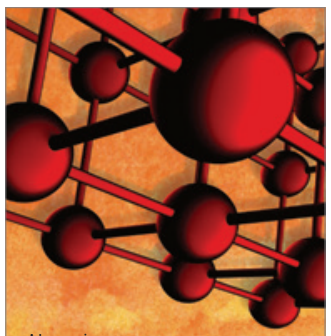

Materials Science and Engineering
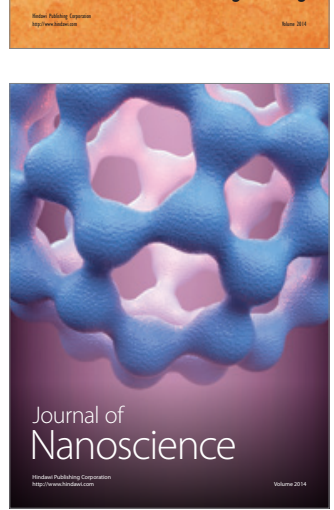
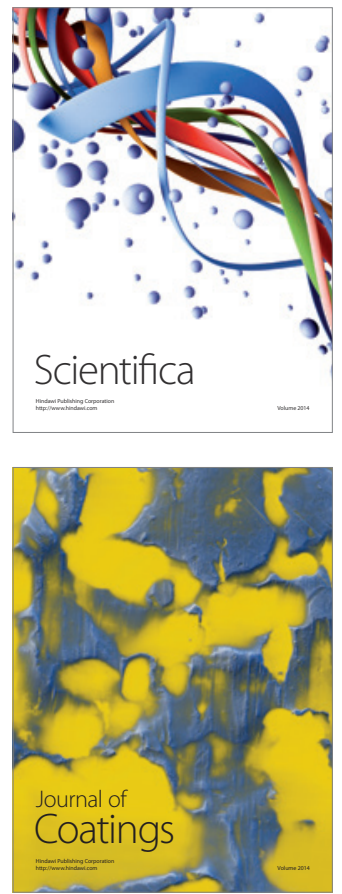
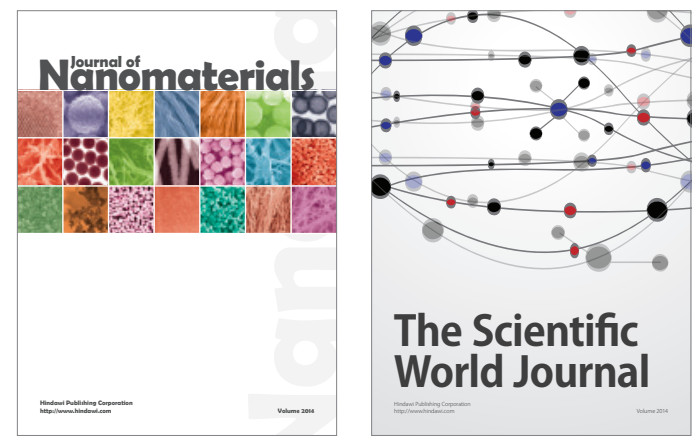

The Scientific World Journal
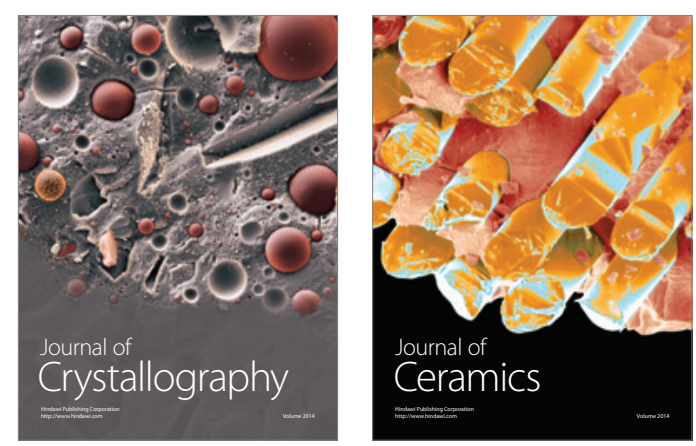
